\title{
An Empirical Study on the Effects of Organizational Cynicism and EVLN Responses on Organizational Commitment and Pro-union behavioral Intentions
}

\author{
Yeon-Yong Seo \\ Doctoral Candidate, Graduate School of Business, Chungbuk National University, Cheongju, Korea
}

Sang-Eon Park*

Professor, School of Business, Chungbuk National University, Cheongju, Korea, Chan-Jung Kim

Assistant Professor, School of Business, Chungbuk National University, Cheongju, Korea

\begin{abstract}
This paper has investigated the effects of employees' organizational cynicism on their organizational commitment and pro-union behavioral intentions in the context of repetitively implementing business innovation program. The cynical responses about the business innovation program \& projects have been classified into four categories; Exit, Voice, Loyalty and Neglect. The research samples have been drawn from managers and office employees at four business sites of conglomerates in Korea. According to the analysis, business innovation program which is continuous and repetitive has made managers and office employees have highly cynical attitudes. In turn, the organizational cynicism has accelerated their Exit and Neglect responses, but shrunk Voice and Loyalty responses. As a result, it has been confirmed that the organizational cynicism has a direct effect on organizational commitment and pro-union behavioral intentions. In addition, it has been concluded that Exit and Neglect had a negative effect on organizational commitment but a positive effect on pro-union behavioral intentions. Even though Voice and Loyalty had a positive effect on organizational commitment, they had no significant effect on pro-union behavioral intentions. Furthermore, no mediating effect has been detected. Implications and suggestions for future research were then discussed.
\end{abstract}

Keywords: Business innovation program, Organizational cynicism, Exit-Voice-Loyalty-Neglect (EVLN), Organizational commitment, Pro-union behavioral intentions

\section{INTRODUCTION}

These days, functional and hierarchical boundaries have been breaking down in many companies. In addition, competition structures have been collapsing. Under these circumstances, business innovation program which creates customer values is the only solution to maintain continuous growth and survival. In fact, it would be the most practical solution to make business innovation activities keep going [1].

Hence, a business innovation program \& project has been not an option but a necessary issue \& task to grow and survive under the limitless competition. Now, a lot of employees are highly aware of the necessity of business innovation program \& project.

In practice, however, a business innovation program \&

\footnotetext{
*Corresponding author E-mail: separk@chungbuk.ac.kr
} Manuscript received May.27, 2011 ; accepted Jun.24, 2011 project has often been symbolically adopted by coercive, normative pressure and institutional circumstance, not based on rational choices to enhance efficiency in order to make it look good to the organization. In addition, it has not been easy to meet various customer needs due to serious competition and rapid technology advance. Furthermore, the lessons learned from the prior innovation project \& activities have not been enough to respond to additional new changes. And an attempt to change the core area of organization has caused a lot of serious resistance among employees.

Therefore, it has been often to fail to accomplish the original plan and performance. In particular, the continuous stimulations of the innovation project achievement while no internal agreement is reached can cause serious stress and fatigue. If employees experience failure repetitively, they become cynical against the innovation program \& project. At the same time, their organizational commitment can also decrease [2].

A poor action plan or absence of proceeding rules could 
be generally a kind of the reason employees' negative response. However, the negligence on employees' cognitive and emotional aspects in the process of proceeding the innovation program \& project has been the main cause of the failure and problem.

Therefore, this paper has attempted to review employees' cynical responses \& attitudes on continuous and repeating business innovation program \& project and investigate their effects on organizational effectiveness.

\section{THEORETICAL BACKGROUND}

\subsection{Business Innovation Program, Organizational Cynicism and EVLN Responses}

So far, many companies have adopted a variety of innovation techniques and programs \& project such as restructuring, reengineering and benchmarking as if fashion.

Therefore, the preceding and resulting variables for success of innovation have been widely studied in terms of organizational structure and organizational psychology by the preceding researchers.

According to these studies, even though the innovation has been successful from the short-term perspective, it would not be easy to achieve the intended performance if employees have a negative response to the program \& project [3].

In particular, the innovation program which has been introduced to coercive, normative, and institutional pressures has neglected employees' cognitive and psychological aspects. In addition, repeating business innovation program \& project without consistent can cause fatigue and cynical behaviors [4].

The cynicism about business innovation program is a part of resistance of innovation as employees' critical opinion and attitudes toward business innovation program [1]. The cynical attitude and behavior are mostly appeared through negative words and actions in the process of proceeding the innovation program \& project.

Although employees have the cynical attitudes and behaviors on the innovation program, they do not always show resistant behaviors. Furthermore, they could show positive behaviors which are toward change and innovation based on various reasons such as personal experience, current situation, and personal philosophy, perspective on their supervisors and organization, and expectation with the change [5].

In addition, resistant response on the innovation program is not always openly exposed. It appears skillful and gradually, various way and intensity control, throughout the innovation project process, but it seems to outwardly support innovation [1].

A lot of studies have been conducted on these various responses and behaviors. As a result, Farrell's EVLN model which has been understood as general response attitude on job dissatisfaction has been used in examining the failure background of business innovation program and resistance types.

Farrell (1983) argued that responses to job dissatisfaction can be aligned along two separate dimensions: constructive / destructive and active / passive. And then as follows, these responses have been differently suggested depending job satisfaction, investment size, quality of alternatives and the relations [6].

(1) Exit refers to an active response to job dissatisfaction such as getting into action and looking for another job, deciding to quit the company, and getting him/herself transferred to another job

(2) Voice is active and constructive behaviors such as talking to the supervisor or coworkers to try and make things better, suggesting solutions to solve the situation and problem, writing a letter to a staff and department to help the problem.

(3) Loyalty refers to the employee response of passively but optimistically waiting and hoping for conditions to improve such as promoting private and public support to the organization, practicing good citizenship and displaying patience for the current setting to improve.

(4) Neglect is a form of passive behavior, such as calling in sick, not dealing with what are happening, coming in late, becoming less interested, marking more errors, and getting time for personal affairs during work hour.

Regarding Farrell's EVLN as independent responses, Withey \& Cooper(1989) proved that the EVLN were correlated with each other.

In other words, (1) In Voice, it is not easy to maintain consistency and estimate predictability due to possibility of retaliation, loss of reputation and emotional cost of confronting people with power. (2) In case of Neglect, there are a possibility of discipline, blocked opportunities, loss of reputation and indirect cost such as sense of failure. In Loyalty, there is waiting for conditions to improve. Therefore, it is not easy to tell the difference between Neglect and Loyalty. (3) Employees can appear a series of acts in sequence based on alternatives when they change their responses or behaviors. To solve a problem, they may take their dissatisfaction, become silent and put up with it, and quit (Voice $\rightarrow$ Loyalty $\rightarrow$ Exit). They can also become silent, request for improvement and leave or become negligent (Loyalty $\rightarrow$ Voice $\rightarrow$ Exit / Neglect) [7].

These organizational cynicism-based EVLN responses are formed and changed depending on the characteristics of innovation projects and organizational environment rather than individual character

\subsection{EVLN, Organizational Commitment and Pro-union behavioral intentions}

In general, an innovation program \& project explicitly and implicitly sets a high stretch goal and promotes innovative behaviors. From a long-term perspective, it enhances productivity and improves quality of labor [8].

Therefore, an innovation program \& project which has been successful from a long-term perspective enhances the workinglevel officials' task autonomy and authority and makes them proud of being an early adopter of the new program and technology. In addition, it can increase organizational commitment and strengthens its image and makes it possible 
for employees to get social support [9].

However, an innovation program \& project has negative aspects behind these positive aspects. In terms of the characteristics of innovation program \& project, working-level officials need to detect, diagnose and improve a problem for themselves. At the same time, they would have work pressure. This kind of work pressure makes them have negative behaviors on innovation, which could in turn decrease organizational effectiveness [10].

In addition, performance-oriented requirement which is systematically and normatively ordered during the innovation project would make unskilled employees believe in performance instrumentality.

As a result, they would become attachment to the union [11]. Meanwhile, if union is formed, those who have not yet joined the union tend to express their complaints through the union when they are dissatisfied with the organization. Unless union is formed, most of them just leave the company [12].

However, it would not be easy for many workers to quit their workplace because their current work place would account for a great portion in their lives, and it would be difficult to get a new job. After all, they would search for a psychological coalition at workplace. In other words, they would join or organize a union [13].

\subsection{Research Model and Hypothesis}

Based on a review on the previous studies, this paper has come up with a research model (Figure1) and proposed hypotheses as follows:

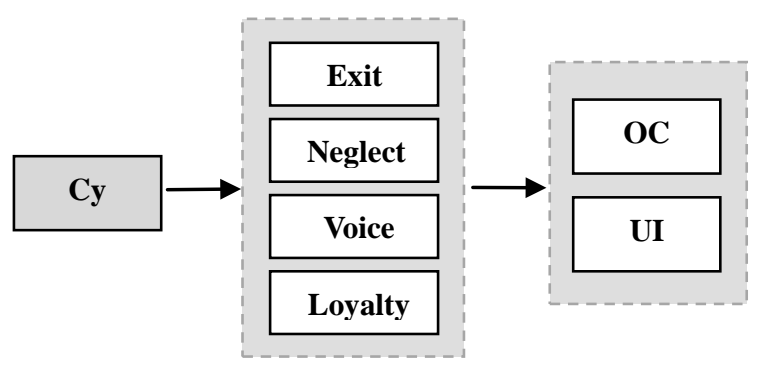

Fig.1. Research Model

in fig.1. and Table

Cy means organizational Cynicism

OC means Organizational Commitment

UI means pro-Union behavioral Intentions

H 1: Organizational cynicism would have a significant effect on EVLN.

1-1: Organizational cynicism would have a positive effect on Exit.

1-2: Organizational cynicism would have a positive effect on Neglect.

1-3: Organizational cynicism would have a negative effect on Voice.

1-4: Organizational cynicism would have a negative effect on Loyalty.
H 2: The organizational cynicism-based EVLN would have a significant effect on organizational effectiveness.

2-1: Exit would have a negative effect on organizational commitment.

2-2: Neglect would have a negative effect on organizational commitment.

2-3: Voice would have a positive effect on organizational commitment.

2-4: Loyalty would have a positive effect on organizational commitment.

2-5: Exit would have a positive effect on pro-union behavioral intentions.

2-6: Neglect would have a positive effect on pro-union behavioral intentions.

2-7: Voice would have a negative effect on pro-union behavioral intentions.

2-8: Loyalty would have a negative effect on pro-union behavioral intentions.

H3. EVLN would mediate the relationship between organizational cynicism and organizational effectiveness which is measured in this study as organizational commitment and pro-union behavioral intentions.

\section{RESEARCH METHOD}

All the sampling survey and definition and measurement of research variables in this paper are as follows:

For this paper, samples have been drawn from four business sites of conglomerates in Korea. The sample survey has been conducted against managers and office employees who have not joined the union and participated in the innovation project more than twice through a questionnaire.

Meanwhile, research variables have been defined and measured as follows. Both reliability and validity per variable have been satisfied.

Organizational cynicism, in terms of independent variable, is defined as negative and passive attitude that employees have experienced during continuous and repeating business innovation program \& project. In accordance with the questionnaire survey by Dean et al. [14], it has been measured using five questions. Factor validity has been satisfied in all five questions, and high reliability (Cronbach $\alpha=.838$ ) has been observed.

Second, organizational commitment has been defined as emotional attitude, which employees work hard to attain an organizational performance, identify their personal vision with company goal, and have psychological attachment and pride for their company. It has been measured using four questions by referring to the studies by Mowday, Steers \& Porter [15] and Lee, Allen, Meyer \& Rhee [16]. Factor validity has been 
satisfied in all four questions, and high reliability (Cronbach $\alpha=.731$ ) has been observed.

Third, pro-union behavioral intentions has been defined as intention to joining union for better benefits after getting rid of the stress from the innovation projects. It has been measured using four questions by referring to the studies by Kelloway et al. [17]. Factor validity has been satisfied in all four questions, and high reliability (Cronbach $\alpha=.730$ ) has been observed.

Fourth, cynical responses about business innovation program \& project have been classified into four categories depending on responses to dissatisfaction and resistance.

(1) Exit refers to a response to information searching for leaving an organization by quitting, transferring, looking for another job or thinking about leaving. (2) Voice is a constructive behavior by discussing about dissatisfying conditions with supervisors and suggesting solutions and taking action to solve the conditions. (3)Loyalty is a positive and cooperative response to a supervisor and department with understanding of the necessity of business innovation programs. (4) Neglect can be defined as negligent behavior, which includes inattention to duties and idling at work.

After choosing two among the EVLN questions which have been used by Farrell (1983), each response has been measured. Factor validity has been satisfied and normal reliability (Cronbach $\alpha>0.6$ ) has been obtained.

\section{RESULTS OF ANALYSES}

The correlation analysis and hypothesis testing in this paper are as follow:

The result of the correlation analysis among variables is shown in Table 1.

The correlation among variables is mostly identical with research hypotheses. In case of Voice, however, a positive direction has been observed in relation with pro-union behavioral intentions in disagreement with hypothesis.

Table 1. Correlations among study Variables

\begin{tabular}{|c|c|c|c|c|c|c|c|c|c|}
\hline & $\mathbf{M}$ & $S$ & Су & $\mathbf{E}$ & $\mathbf{N}$ & V & $\mathbf{L}$ & OC & UI \\
\hline Су & 3.35 & .71 & 1.00 & & & & & & \\
\hline E & 2.46 & .86 & $.26^{* *}$ & 1.00 & & & & & \\
\hline $\mathbf{N}$ & 2.62 & .66 & $.36^{* *}$ & $.42^{* *}$ & 1.00 & & & & \\
\hline V & 3.28 & .69 & $-.14^{*}$ & .03 & $-.15^{\star *}$ & 1.00 & & & \\
\hline $\mathbf{L}$ & 3.55 & .61 & -.11 & $-.14^{*}$ & $-.22^{\star *}$ & $.45^{\star \star}$ & 1.00 & & \\
\hline OC & 3.67 & .56 & $-.25^{* \star}$ & $-.20^{\star *}$ & $-.34^{* *}$ & $.32^{* *}$ & $.41^{* \star}$ & 1.00 & \\
\hline UI & 2.95 & .70 & $.32^{* *}$ & $.43^{* *}$ & $.38^{\star \star}$ & .02 & -.06 & -.05 & 1.00 \\
\hline
\end{tabular}

** $\mathrm{P}<.01, * \mathrm{P}<.05$

Meanwhile, the results of hypothesis testing are as follows:

Testing H1: Relationships between organizational cynicism and EVLN (Table 2)

The organizational cynicism caused by continuous and repeating business innovation program \& project had a positive effect on Exit and Neglect but negative effect on Voice and Loyalty.

Table 2. Results of Multiple Regression Test of Organizational Cynicism on EVLN

\begin{tabular}{c|cccc}
\hline & $\mathbf{E}$ & $\mathbf{N}$ & $\mathbf{V}$ & $\mathbf{L}$ \\
\hline \hline $\mathbf{C y}$ & $4.545^{\star \star *}$ & $6.751^{\star *}$ & $-2.84^{\star *}$ & $-2.195^{*}$ \\
\hline $\mathrm{R}$ & .272 & .376 & .275 & .263 \\
$\mathrm{R}^{2}$ & .074 & .141 & .076 & .069 \\
$\mathrm{~F}$ & $4.72^{\star *}$ & $9.69^{\star \star}$ & $4.82^{\star \star}$ & $4.40^{\star \star}$ \\
\hline
\end{tabular}

$* * \mathrm{P}<.01, * \mathrm{P}<.05$

Testing H2: Relationships between EVLN an organizational commitment / pro-union behavioral intentions. (Table 3, 4)

Both Exit and Neglect had a negative effect on organizational commitment but positive effect on pro-union behavioral intentions. (Table 3) On the contrary, Voice and Loyalty had a significant positive effect on organizational commitment but a negative effect, insignificant, on pro-union behavioral intentions. (Table 4)

Table 3. Results of Multiple Regression Tests of EVLN

\begin{tabular}{|c|c|c|c|c|}
\hline & on & Organizational & Commitmen & \\
\hline & $\mathbf{E}$ & $\mathbf{N}$ & V & $\mathbf{L}$ \\
\hline OC & $-3.97^{* *}$ & $-5.96^{* *}$ & $4.88^{* *}$ & $6.77^{* *}$ \\
\hline $\mathrm{R}$ & .37 & .44 & .40 & .46 \\
\hline $\mathrm{R}^{2}$ & 14 & 19 & .16 & .21 \\
\hline $\mathrm{F}$ & $9.31^{* *}$ & $13.64^{\star *}$ & $11.08^{\star \star}$ & 15.90 ** \\
\hline
\end{tabular}

** $\mathrm{P}<.01, * \mathrm{P}<.05$

Table 4. Results of Multiple Regression Tests of EVLN on Pro-union Behavioral Intentions

\begin{tabular}{c|cccc}
\hline & $\mathbf{E}$ & $\mathbf{N}$ & $\mathbf{V}$ & $\mathbf{L}$ \\
\hline \hline UI & $7.84^{* *}$ & $7.52^{* *}$ & -.289 & -1.36 \\
\hline $\mathrm{R}$ & .46 & .44 & .20 & .52 \\
$\mathrm{R}^{2}$ & .21 & .20 & .04 & .27 \\
$\mathrm{~F}$ & $15.29^{\star *}$ & $14.26^{* *}$ & $2.50^{\star *}$ & $13.16^{\star *}$ \\
\hline
\end{tabular}

** $\mathrm{P}<.01, * \mathrm{P}<.05$

Testing H3: EVLN' mediating effect between organizational cynicism and organizational commitment / pro-union behavioral intentions (Table 5, 6).

This paper has investigated that EVLN plays a mediating 
role between organizational cynicism and organizational commitment, also between organizational cynicism and prounion behavioral intentions, except Voice and Loyalty.

According to the analysis, both Exit and Neglect had a negative mediating effect between organizational cynicism and organizational commitment but Voice and Loyalty had a positive mediating (Table 5).

Table 5. EVLN' mediating effect between organization cynicism and organization commitment

\begin{tabular}{|c|c|c|c|c|c|c|c|c|c|}
\hline & \multicolumn{4}{|c|}{1 step } & \multirow{2}{*}{$\begin{array}{l}\text { 2step } \\
\text { OC }\end{array}$} & \multicolumn{4}{|c|}{3 step } \\
\hline & $\mathbf{E}$ & $\mathbf{N}$ & $\mathbf{V}$ & $\mathbf{L}$ & & E & $\mathbf{N}$ & V & $\mathbf{L}$ \\
\hline Cy & $4.6^{* *}$ & $6.8^{* *}$ & $-2.8^{\star *}$ & $-2.2^{*}$ & -5.0 ** & $-4.2^{\star \star}$ & $-3.2^{\star * *}$ & $-4.4^{* *}$ & $-4.5^{\star \star}$ \\
\hline$\beta$ & - & - & - & - & -.27 & -.23 & -.18 & -.23 & -.23 \\
\hline EVLN & - & - & - & - & - & $-2.9 * \star$ & $-4.5^{\star *}$ & $4.4^{* *}$ & $6.4^{* *}$ \\
\hline $\mathrm{R}^{2}$ & .07 & .14 & .08 & .07 & .16 & .19 & .22 & .21 & .26 \\
\hline
\end{tabular}

$* * \mathrm{P}<.01, * \mathrm{P}<.05$

And both Exit and Neglect had a positive mediating effect between organizational cynicism and pro-union behavioral intentions. Voice and Loyalty, however, no significant mediating effect has been observed between organizational cynicism and pro-union behavioral intentions (Table 6).

Table 6. EVLN' mediating effect between organization cynicism and pro-union behavioral intentions

\begin{tabular}{|c|c|c|c|c|c|c|c|c|c|}
\hline & \multicolumn{4}{|c|}{1 step } & \multirow{2}{*}{\begin{tabular}{|c} 
2step \\
UI
\end{tabular}} & \multicolumn{4}{|c|}{3 step } \\
\hline & $\mathbf{E}$ & $\mathbf{N}$ & $\mathbf{V}$ & $\mathbf{L}$ & & E & $\mathbf{N}$ & $\mathbf{V}$ & $\mathbf{L}$ \\
\hline Сy & $4.6^{* \star}$ & $6.8^{* *}$ & $-2.8^{\star *}$ & $-2.2^{*}$ & $5.7^{* k}$ & $4.2^{* *}$ & $3.4^{* *}$ & $5.7^{* *}$ & $5.5^{* *}$ \\
\hline$\beta$ & - & - & - & - & .31 & .22 & .19 & .32 & .30 \\
\hline EVLN & - & $\cdot$ & - & - & - & $6.7^{* *}$ & $5.9^{* *}$ & .63 & -.71 \\
\hline $\mathrm{R}^{2}$ & .07 & .14 & .08 & .07 & .14 & .25 & .23 & .14 & .14 \\
\hline
\end{tabular}

** $\mathrm{P}<.01, * \mathrm{P}<.05$

\section{CONCLUSION}

\subsection{Summary and Implications}

Summary of this study and its theoretical, managerial implication are as followings:

First, the organizational cynicism-based EVLN responses had different efforts on organizational effectiveness by EVLN type. Both Exit and Neglect had a negative effect on organizational commitment but positive effect on pro-union behavioral intentions. Especially, both Voice and Loyalty had a positive effect on organizational commitment but didn't have a significant negative effect on pro-union behavioral intentions.
In other words, employees recognized themselves as an organization man, under business innovation, which is systematically ordered as a daily routine work. In fact, they believe that it is the best choice to follow their supervisor and team; however, there is a possibility that unless the expectation for improvement is satisfied, the constructive response could change into destructive response.

Therefore, it is important to pay attention to employees' responses with open mind and reinforce the necessity of business innovation program through the innovation promotion program which encourages employees to participation.

Second, the meaningful results (Table 1) which have been observed in this paper are not significant in correlation between Voice and pro-union behavioral intentions, an insignificant positive relation $(\mathrm{r}=.02)$ has been detected. In addition, Voice in Table 4 didn't have a significant negative effect on pro-union behavioral intentions.

In other words, it is necessary to have special attention in Voice. Even if employees say something for constructive improvement, it could be regarded as negative or inflammatory attitudes to their supervisor or company. Nevertheless, it is necessary to have a close attention to the responses considering the hidden massage of noticeable response.

In particular, these efforts and insight are essential in establishing moral and organizational culture, achieving the successful promotion and spreading business innovation program.

Third, organizational cynicism had a positive effect $\left(\mathrm{t}=5.7^{* *}\right)$ on pro-union behavioral intentions (Table 6) and a negative effect $\left(\mathrm{t}=-5.0^{* *}\right)$ on organizational commitment (Table 5). It has been confirmed that organizational cynicism had a direct impact on non-union members' pro-union behavioral intentions as an independent variable.

In other words, it has been proven that organizational cynicism could be decisive factor on pro-union behavioral intentions. The possibility of join the union, which is non-union members, such as managers and office employees, increases due to the onset of the time for a multiple union system. It is likely that many managers and office employees who have high organizational cynicism would join the union.

For businesses to which continuous business innovation program is essential, therefore, it is important to approach organizational cynicism and related reactions from the union and labor management perspectives.

\subsection{Suggestions}

Until now, most preceding studies on EVLN responses have been focused on the individual trait dimensions. This paper, however, has enlarged the span of EVLN study because it included the variables of organizational effectiveness such as organizational commitment and pro-union behavioral intentions in the context of business innovation.

Finally, this paper suggests the directions for future researches as followings: 
First, this study is a cross-sectional research conducted in a special point of time. For the future research, longitudinal research design is needed, because employee' responding behavior can be changed according to the various psychological situations of business innovation programs.

Second, this study was implemented by the questionnaire survey in the interrelated enterprises of conglomerate in Korea. So, future study is needed to include more wide samples, because various types of employee' responding behavior can appear in the contexts of different organizational cultures and climates.

\section{REFERENCES}

[1] C.R. Carlson, and W.W. Wilmot, "Innovation”, Gimmyoung Publishers. Inc, 2008, pp.23 43.

[2] S.K. Piderit, "Rethinking resistance and recognizing ambivalence: A multidimensional view of attitudes toward an organizational change", Academy of Management Review, 25(4), 2000, pp.783 794.

[3] T.N. Gilmore, G.P. Shea, \& M. Useem, "Side effort of corporate transformations”, Journal of Applied Behavioral Science, 33, 1997, pp.174 189.

[4] H.S. Seol, and S.G. Ji, "An Exploratory Study on Antecedents of Cynicism about Organizational Innovation", The Korean Academic Association of Business Administration, Vol. 18, No. 3, 2005, pp.1349 1367.

[5] D.A. Yousef, "Organizational commitment and job satisfaction as predictors of attitudes toward organizational change in a non-western setting”, Personal Review, 29(5), 2000, pp.568 592.

[6] D. Farrell, "Exit, Voice, Loyalty and Neglect as responses to job dissatisfaction: A multidimensional scaling study", Academy of Management Journal, 26, 1983, pp. 596 607.

[7] M.J. Withey, and W.H. Cooper, "Predicting Exit, Voice, Loyalty and Neglect” Administrative Science Quarterly, 34, 1989, pp.521 539.

[8] D. Bunce, \& M. West, "Stress Management and Innovation Interventions at work", Human Relation, 49 (2), 1996, pp.209 232.

[9] G.W. Downs Jr., \& L.B. Mohr, “Conceptual Issues in the Study of Innovation”, Administrative Science Quarterly, 21, 1980, pp.700 714.

[10] S.H. Song, and K.J. Hwang, “The Effect of Employees' Dissatisfaction for Business Innovation and Their Job Alienation on Organizational Effectiveness", Korean Management Review, Vol. 14, No 1, pp.105 134.

[11] J.M. Lee and D.Y. Shin, "Dual Commitment and Its Antecedents and Mediator: The Case of a Workplace Implementing New Management Practices”, Korean Journal of Management, Vol. 11, No. 2, 2003, pp.1 39.

[12] G.J. Borjas, "Job satisfaction, wages, and unions", Journal of Human Resources, 14, 1979, pp.21 39
[13] J.H. Jung, "Relationship between employees' to firm satisfaction and Trade Union commitments", Seoul University, Doctoral Dissertation, 1992

[14] J.W. Dean, P. Brandes, \& R. Dharwadkar, “Organizational cynicism”, Academy of Management Review, 23, 1998, pp.341 352.

[15] R.T. Mowday, R.M. Steers, \& L.W. Porter, The measurement of organizational commitment, Journal of Vocational Behavior, 14, 1979, pp.224 247.

[16] K. Lee, N.J. Allen, \& J.P. Meyer\& K.Y. Rhee, "The three component model of organizational commitment: An application to South Korea”, Applied Psychology: An International Review, 50, 2001, pp.596 614.

[17] K. Kelloway, V. Catano, \& R. Southwell, The Construct validity of Union Commitment: Development and dimensionality of a Shorter Scale. Journal of Occupational and Organizational Psychology, 65, 1992, pp.197 211.

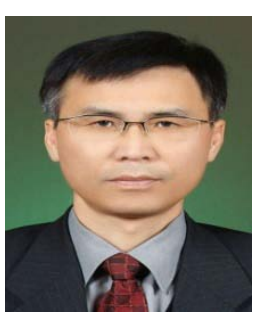

Yeon-Yong Seo

He is a doctoral course student of Chungbuk National University. His main research interests include HRM, Labor and industrial Relation

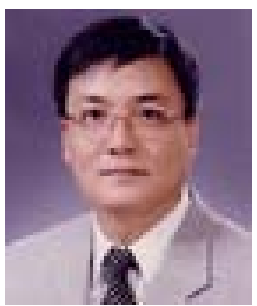

Sang-Eon Park

He is currently an organizational Behavior /Organizational Theory professor of Chungbuk National University. His main research interests include Emotional Labor, Job Burnout and Business Innovation.

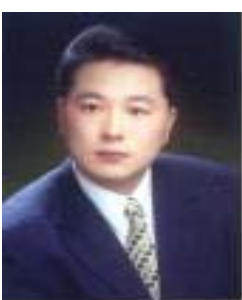

\section{Chan-Jung Kim}

He is currently a HRM professor of Chungbuk National University. His main research interests include HRM, Industrial Relation and Business Ethics. 